\title{
BUILDING ORTHOPAEDIC REGISTRIES AND DATABASES: SOONER THE BETTER
}

Sir,

National joint registries have been successfully established in Sweden, Britain, Norway and Australia to record total joint replacements. ${ }^{[1-4]}$ The United States is clearly heading this way 
as well. They have been immensely helpful in improving the joint replacement practice in these countries.

A joint registry helps in continuous improvement of outcomes and aids the learning process. Total joint replacement has become popular in India but has a long way to go before it gets streamlined. Serious problems with implant survival are being reported with certain types of prosthesis and bearing surfaces in European countries. However, data from elsewhere cannot always be generalized because of geographical, cultural and anatomical variations. Some newer implants such as metal on metal joint replacements are being used in India with little emphasis on follow-up of these patients. Nobody knows who is using these implants and what happens to the patients in the longterm. Orthopaedic surgeons in India would be soon facing with a mammoth task of revision operations as the life expectancy improves and equally patient expectations increase. It would be worthwhile for Indian orthopaedic surgeons to have their own results at hand and to keep track of their practice. Information from the joint registries can be used for patient education as well.

Various databases related to hip fractures and major trauma have been recently started in the UK. These help in auditing the current practice and strive for continuous improvement of fracture and geriatric services. ${ }^{[5-7]}$ Indian orthopaedic surgeons should be looking forward to similar projects in future.

It is better to consider the idea of establishing joint registries and fracture databases in India at an earlier date than later. It can only become more difficult as we wait because a large number of these implants would be unaccounted for by the time we wake up to this idea.

The large data collection process surely has economic implications but this is worth considering seriously. Further, the logistics involved can be huge in a large country like India but are easier to establish before the problem becomes even bigger. India, with an information technology niche should be able to adopt these national databases with government and industry encouragement. They will go a long way to improve the health outcomes in India particularly related to orthopaedics.

KIRAN SINGISETTI

University Hospital of North Tees, Stockton on Tees, TS19 8PE, United Kingdom.

Correspondence:

Mr. Kiran Singisetti, Department of Trauma and Orthopaedics, University Hospital of North Tees, Stockton on Tees, TS19 8PE, United Kingdom. E-mail: kiransingisetti@gmail.com DOI: 10.4103/0019-5359.48459

\section{REFERENCES}

1. Swedish Joint Registry. Available from: http:// www.jru.orthop.gu.se/.[last accessed 2009 Jan 1].

2. National Joint Registry, England and Wales (NJR). Available from: http://www.njrcentre.org.uk/.[last accessed 2009 Jan 1].

3. The Norwegian Arthroplasty Register. Available from: http://www.haukeland.no/nrl/.[last accessed 2009 Jan 1].

4. Australian Orthopaedic Association. National Joint Replacement Registry. Available from: http://www.dmac.adelaide.edu.au/aoanjrr/.[last accessed 2009 Jan 1]. 
5. The Scottish Hip Fracture Audit (SHFA). Available from: http://www.shfa.scot.nhs.uk/.[last accessed 2009 Jan 1].

6. National Hip Fracture Database (NHFD). Available from: http://www.nhfd.co.uk/.[last accessed 2009 Jan 1].

7. Trauma and audit research network. Available from: https://www.tarn.ac.uk/.[last accessed 2009 Jan 1]. 